\title{
Noyon - Les Forbus
}

Hélène Dulauroy-Lynch

URL : http://journals.openedition.org/adlfi/5615

ISSN : 2114-0502

Éditeur

Ministère de la culture

\section{Référence électronique}

Hélène Dulauroy-Lynch, " Noyon - Les Forbus », ADLFI. Archéologie de la France - Informations [En ligne], Picardie, mis en ligne le 01 mars 2007, consulté le 03 mai 2019. URL : http:// journals.openedition.org/adlfi/5615

Ce document a été généré automatiquement le 3 mai 2019.

(c) Ministère de la Culture et de la Communication, CNRS 


\title{
Noyon - Les Forbus
}

\author{
Hélène Dulauroy-Lynch
}

\section{Identifiant de l'opération archéologique : 9146}

Date de l'opération : 2007 (EX)

1 Une demande anticipée de prescription, préalable à la construction d'un stade d'athlétisme a motivé la réalisation d'un diagnostic archéologique. Les terrains concernés se localisent au nord-est de la ville, à l'extérieur de la ville antique et médiévale, sur la pente sud-ouest du mont Saint-Siméon.

2 L'évaluation archéologique (20 sondages et 4 sondages profonds) a permis de mieux comprendre les perturbations récentes qui ont affecté les côteaux du mont Saint-Siméon. En effet, un grand tiers nord-ouest du site n'avait pas été notablement bouleversé jusqu'ici et les quelques rares vestiges anciens mis au jour, l'ont été dans ce secteur.

3 Il s'agit d'abord d'un ensemble homogène de pièces de silex particulièrement frais attestant d'une production laminaire, associée à des burins. Cependant, l'étude géomorphologique a montré que cet ensemble n'était pas en place.

4 Un peu de mobilier résiduel médiéval a en outre été mis au jour, en petite quantité, dans les parties hautes du site. Ce mobilier n'était pas non plus en place: la couche sableuse où ils ont été trouvés témoignent de leur déplacement sur la pente.

5 Notons qu'aucune trace de la culture de la vigne, pourtant pratiquée dans cette zone, n'a été remarquée, si ce n'est un fossé parcellaire.

$6 \quad$ Le reste de la parcelle a été fortement perturbé pendant les deux siècles derniers. Elle a en effet servi de carrière de sable comme en témoigne les profonds décaissements et les accidents du terrain qui la caractérisent. Les lieux ont alors servi de dépotoir jusqu'à nos jours et les chances de trouver un site antérieur au $\mathrm{XX}^{\mathrm{e}} \mathrm{s}$. étaient donc nulles.

7 Enfin, l'ensemble de la parcelle a été fortement marqué par les combats de la première guerre mondiale dont témoignent les nombreux impacts d'obus. 
INDEX

operation Expertise (EX)

Index chronologique : ép. contemporaine, Moyen Âge, Néolithique

Index géographique : Picardie, Oise, Noyon

Thèmes : burin, carrière, dépotoir, fossé, géomorphologie, guerre, industrie lithique, lamelle, parcellaire, silex

\section{AUTEURS}

\section{HÉLÈNE DULAUROY-LYNCH}

COLL 